\title{
Anabases
}

ANABASES Traditions et réceptions de l'Antiquité

\section{La culture juridique romaine dans les papyri : quelques réflexions actuelles}

Hélène Ménard

\section{(2) OpenEdition}

1 Journals

Édition électronique

URL : http://journals.openedition.org/anabases/5505

DOI : 10.4000/anabases.5505

ISSN : 2256-9421

Éditeur

E.R.A.S.M.E.

\section{Édition imprimée}

Date de publication : 20 octobre 2015

Pagination : 248-253

ISSN : 1774-4296

\section{Référence électronique}

Hélène Ménard, «La culture juridique romaine dans les papyri : quelques réflexions actuelles »,

Anabases [En ligne], 22 | 2015, mis en ligne le 20 octobre 2018, consulté le 21 octobre 2019. URL:

http://journals.openedition.org/anabases/5505; DOI : 10.4000/anabases.5505 


\section{Droit et réception de l’Antiquité}

\section{La culture juridique romaine dans les papyri: quelques réflexions actuelles}

\section{Hélène MÉnARD}

Les sources permettant d'approcher la culture juridique romaine reposent sur des supports variés. L'épigraphie juridique est l'une des disciplines les étudiant, une autre étant constituée par la papyrologie juridique ${ }^{39}$. Le terme de "papyrologie» doit être compris dans son acception la plus large ${ }^{40}$. Deux branches de la papyrologie sont habituellement distinguées : d'une part la papyrologie littéraire, d'autre part la papyrologie documentaire, elle-même subdivisée en papyrologie historique et papyrologie juridique. Cette dernière «fonde sa spécificité sur les papyrus conservant des cas de la pratique, des traités ou des codes relevant des droits de l'Antiquité ${ }^{41}$ '. La parution à Leipzig, en I89I, de l'ouvrage de Ludwig Mitteis, Reichsrecht und Volksrecht in den östlichen Provinzen des römischen Kaiserreichs, mit Beiträgen zur Kenntnis des griechischen Rechts und der spätrömischen Rechtsentwicklung, est considérée comme l'acte de naissance de la papyrologie juridique, avec la somme Grundzüge und Chrestomathie der Papyruskunde, publiée par lui-même et Ulrich Wilcken en ${ }_{1912}{ }^{42}$. La papyrologie juridique constitue donc une discipline assez

39 Voir L. Wenger, Quellen des römischen Rechts, Vienne, I953; J.-L. Ferrary, “L'épigraphie juridique romaine: historiographie, bilan et perspectives », in Le monde romain à travers l'épigraphie: méthodes et pratiques. Actes du XXIVe Colloque international de Lille (8-Io novembre 200I), J. Desmulliez, Chr. Нö̈t-Van Cauwenberghe (dir.), Lille, 2005, p. 35-7o. B. Legras, “La papyrologie documentaire grecque en 2005: bilan et perspectives», Anabases I (2005), p.215-23r: “[...] la discipline étudiant les textes antiques venus d'Égypte écrits à l'encre, qu'ils soient écrits sur papyrus, sur tessons (ostraca), tablettes de bois, cuir, parchemin, lin, etc.» (p.2I7), avec deux précisions: les tablettes en bois incisées relèvent également de ce domaine; les papyri ne proviennent pas tous d'Égypte.

41 Id., p.220.

42 L. Wenger, "The Importance of Greek Papyrology in the study of roman law », BIDR, I936-I937, p. 42I-427, ici p. 422; H.-A.Rupprecht, «Zu Entwicklung, Stand und Aufgaben 
récente, qui se définit surtout par l'étude de textes sur des supports dont la particularité est d'être manuscrits, avec un spectre très large de contenu ${ }^{43}$.

\section{Les papyri: des documents pour une histoire du droit et de la justice}

La papyrologie juridique s'appuie sur des dossiers documentaires provenant essentiellement de l'Égypte gréco-romaine ${ }^{44}$. Sont à verser dans son champ des documents juridiques privés (contrats de mariage, de vente, de travail, etc.) mais aussi des décisions publiques émanant des empereurs comme des préfets d'Égypte, ou encore des procèsverbaux judiciaires ou des ordres d'arrestations ${ }^{45}$. Les pétitions, ces plaintes adressées aux autorités pour engager une procédure, sont également connues en nombre. Enfin les papyri fournissent des données précieuses sur la littérature juridique (ainsi pour les Institutes de Gaius $\left.{ }^{46}\right)$.

L'étude des pétitions a donné lieu à des ouvrages récents, qui permettent de mieux appréhender la culture juridique en Égypte à l'époque romaine.

La réflexion de Benjamin Kelly s'appuie sur l'analyse de 568 pétitions et 227 procèsverbaux d'audience ${ }^{47}$ :

The documents can therefore be used to examine issues relating to the legal culture of Roman Egypt such as the relationship between official adjudication and other methods of dispute resolution, expectations relating to official adjudication, and the ways in which officials processed requests fot dispute resolution ${ }^{\mathbf{4 8}}$.

der juristischen Papyrologie », in Akten des 23. Internationalen Papyrologen-Kongress. Wien, 22-28 Juli 20or, B. Palme (hg.), Vienne, 2007, p.623-63i, ici p.623.

43 B. Legras, "La papyrologie juridique grecque: la formation d'une discipline», in V.Azoulay, R. Gherchanos, S. Lalanne (éd.), Le banquet de Pauline Schmitt Pantel. Genre, moeurs et politique dans l'Antiquité grecque et romaine, Paris, Publications de la Sorbonne, 20I2, p.559-57i; B.Anagnostou-Canas, “L'actualité européenne de la papyrologie juridique », in Grecs, Juifs, Polonais. À la recherche des racines de la civilisation européenne, Varsovie-Paris, Académie polonaise des sciences, 2006, p. IoI-ı6.

44 Des dossiers papyrologiques provenant d'autres régions de l'empire, ont été étudiés, en particulier les papyri du Moyen Euphrate, édités par D.Feissel et J.Gascou («Documents d'archives romains inédits du Moyen Euphrate (III ${ }^{\mathrm{e}} \mathrm{s}$. apr. J.-C.)», CRAI, I989, I33(3), p.535-56r et pour les pétitions, voir Journal des Savants, I995, p.65-II9).

45 B. Palme, “The range of documentary texts : types and categories », in R.S. Bagnall (éd.), The Oxford Handbook of Papyrology, Oxford, 20II, p.358-394, en particulier p.363-37o et $374-377$.

46 B. Anagnostou-Canas, "L'actualité européenne de la papyrologie juridique», in Grecs, Juifs, Polonais, p. I04, n. 4.

47 B. Kelly, Petitions, Litigation, and Social Control in Roman Egypt. Oxford Studies in Ancient Documents, Oxford, Oxford Univ. Pr., 201.

48 B. Kelly, Petitions, p. Io. 
La problématique majeure est de voir en quoi les procédures initiées par les pétitions, permettant la résolution des litiges, participent du contrôle social. Pour l'Égypte romaine, il ne faut pas oublier la préexistence d'une culture juridique, ni la complexité et la variété des modalités possibles pour le règlement d'un litige, notamment «dans l'ombre de la $\operatorname{loi}^{49}$ » : la pétition et le procès ne représentent pas les derniers recours pour régler un différend mais jouent un rôle important dans sa résolution ${ }^{50}$.

Les pétitions sont également au cœur de l'ouvrage d'Ari Bryen sur la violence dans l'Égypte romaine ${ }^{51}$. Il consacre en particulier un chapitre (The Work of Law, p.126-i64) aux stratégies des plaignants qui s'adressent aux autorités afin d'obtenir la réparation des violences subies et la punition des auteurs. Il cherche ainsi à évaluer le rapport de la population au système judiciaire, ainsi que la connaissance du droit que ces pétitions reflètent. Son analyse s'inspire de l'anthropologie juridique. Il adosse également sa réflexion aux travaux de Robert Cover et aux notions de weak legal pluralism et de strong legal pluralism $^{52}$. Un dossier est particulièrement intéressant et illustre sa démarche. Il s'agit d'une pétition connue par deux papyri, les P. Cair. inv. I0269 et I0270, qui en proposent des versions différentes, l'une d'elles pouvant être interprétée comme un brouillon avec des corrections de forme comme de contenu ${ }^{53}$. Le choix d'un certain nombre de termes semble ainsi indiquer la volonté de se conformer à un langage juridique ${ }^{54}$. Ari Bryen penche donc en faveur d'un strong legal pluralism: les individus sont encouragés, par le biais des pétitions, à élaborer des exposés dont certains éléments ressortissent au droit. Ces mêmes pétitions sont elles-mêmes validées en devenant archives, se faisant alors matériau d'une réflexion juridique ultérieure ${ }^{55}$.

49 Expression reprise de R.H. Mnookin et L. Kronhauser, «Bargaining in the Shadow of the Law: the Case of Divorce ", Yale Law Journal 88 (1979), p. $950-997$.

50 B. Kelly, Petitions, p. 244-286.

51 A. Bryen, Violence in Roman Egypt. A Study in Legal Interpretation, Philadelphia, University of Pennsylvania Pr., 2013.

52 A. Bryen, Violence, p. I42: Weak pluralism designates a plural regime in which the state nevertheless monopolizes law-creating or delegates these powers to various authorized groups while preserving distinctions among its subjects. It can take various forms: the state can recognize and legitimate different practices, allowing them to stand as semiautonomous systems of jurisdiction. [...] Strong legal pluralism, on the other hand, entails a claim that "law" can exist independent of state authority. In such a system, different groups create and reinforce normative orders, define what is right and wrong, use tactics of social control to enforce these normative visions, and thus make law as well. These tactics of social control can be more or less formal or effective-they range from shaming and moral censure, at one end, to brute violence against transgressors of the normative order at the other.

53 Sur la pratique des corrections dans les pétitions, voir R. LuiseLLI, «Authorial Revision of Linguistic Style in Greek Papyrus Letters and Petitions (A.D. I-IV)», in T.V.Evans, D.D. Оввілк (éd.), The Language of the Papyri, Oxford, Oxford Univ. Pr., 2010, p. 7i-g6.

54 A. Bryen, Violence, p. I56-i63.

55 A. Bryen, Violence, p. 164 . 
L'intérêt porté à la forme narrative, à la langue, est également présent dans des travaux récents, comme dans le recueil d'articles édité par T.V.Evans et D.D. Obbink, The Language of the Papyri ${ }^{56}$ ou dans certains chapitres de l'Oxford Handbook of Papyro$\log y^{57}$. La réflexion se porte essentiellement sur l'utilisation du latin, langue du droit, et son influence sur le grec dans les documents de la pratique ${ }^{58}$.

\section{Une entreprise au croisement des disciplines: "Rediscovering the hidden structure. A new appreciation of Juristic Texts and Patterns of Thought in Late Antiquity " (RedHis).}

L'intérêt renouvelé pour les papyri est souligné par un projet européen (ERC advanced grant), dirigé par Dario Mantovani (Principal Investigator, université de Pavie) et Luigi Pellecchi (Senior Staff, université de Pavie). S'inscrivant dans une réflexion sur la culture juridique de l'Antiquité tardive, ce projet cherchera à comprendre comment les textes juridiques classiques, avec leurs gloses, circulaient, étaient lus et étudiés, et par là-même, comment ils pouvaient en constituer le ferment, dans les écoles comme dans les tribunaux. Il s'agit donc de reconstituer les liens tissés entre les œuvres des juristes classiques, leur enseignement dans les écoles de droit (Beyrouth, Constantinople) participant à la formation des juristes d'époque tardive, et la législation impériale, à travers les logiques de pensée mises en œuvre. La culture juridique, du $\mathrm{II}^{\mathrm{e}}$ siècle au vi ${ }^{\mathrm{e}}$ siècle, pourra ainsi être réévaluée à une plus juste mesure ${ }^{59}$. La conservation de fragments d'œuvres des juristes en dehors du Digeste, permet en effet de retrouver un état de ces œuvres, antérieur à la compilation, mais aussi de connaître des œuvres non intégrées au Digeste.

L'étude des papyri, au sens le plus large, offre à cet égard une approche particulièrement intéressante et, on peut l'espérer, féconde. En effet les documents fournissent des éléments sur la structure même des textes juridiques, sur leur division en tituli (c'est le cas par exemple pour les Sentences de Paul ou les traités d’Ulpien) mais également par les

56 T.V. Evans, D.D. Obbink (éd.), The Language of the Papyri, Oxford, Oxford Univ. Pr., 2010.

57 R.S. Bagnall (éd.), The Oxford Handbook of Papyrology, Oxford, Oxford Univ. Pr., 2oog.

58 Parmi de nombreuses références, on citera en particulier les pages consacrées par Jean-Luc Fournet au latin comme langue de la loi (J.-L.Fournet, "The Multilingual Environment of Late Antique Egypt: Greek, Latin, Coptic, and Persian Documentation », ici p. 425-427 et E. Dickey, “Latin Influence and Greek Request Formulae », in T.V. Evans, D.D. Obbink, The Language of the Papyri, p.208-220; J.G.KeEnan, J.G.Manning, U. Yiftach-Firanko (éd.), Law and Legal Practice in Egypt from Alexander to the Arab Conquest. A Selection of Papyrological Sources in Translation, with Introductions and Commentary, Cambridge, New York, Cambridge University Pr., 20I4, chap.3: "The Languages of the Law ».

59 Sur cetteidée d'un déclin de la culture juridique, soulignée par l'adjectif “ postclassique », voir J.Harries, "Roman Law and Legal Culture», in The Oxford Handbook of Late Antiquity, Oxford, Oxford Univ. Pr., 2012. 
gloses, ces annotations commentant le corps central du document, soit en marge, soit de façon interlinéaire.

L'une des premières tâches du programme consiste donc à collecter papyri (au nombre d'une cinquantaine, dont une partie est inédite) et parchemins, datés du $\mathrm{II}^{\mathrm{e}}$ au vi ${ }^{\mathrm{e}} \mathrm{s}$. ap. J.-C. (avant les compilations justiniennes) et d'en proposer une édition critique des textes latins et grecs traduits en anglais et en italien. Le site internet (http://redhis.unipv.it/), déjà en activité, accueillera des ressources textuelles et bibliographiques ${ }^{60}$. Un article propose un exemple de la méthode suivie, qui se veut une approche globale du document: après une description codicologique et paléographique, le contenu est analysé, avant l'édition et le commentaire du texte ${ }^{61}$. La comparaison avec les versions du Code Théodosien (CTh. 6, 35, I4 et I2, I, I84, en 423) permet en effet de redéfinir la nature du texte, puisqu'il s'agit d'une constitution d'Honorius et de Théodose II, alors qu'il avait été perçu lors de sa première édition en 201 comme une interpretatio ${ }^{62}$. Il ne saurait être retenu comme un témoignage de la littérature jurisprudentielle.

S'il participe à la reconstitution des textes juridiques (qui en est une étape indispensable), le projet vise aussi à saisir la pensée créative des juristes romains, sa diffusion et sa réappropriation dans différents contextes, à l'époque de la rédaction des Codes.

La culture juridique romaine est au cœur de ces différentes approches, qui lui redonnent toute sa complexité et son épaisseur ${ }^{63}$. Elle se laisse saisir aussi bien par les pétitions qu'au travers des textes juridiques et normatifs, tant par une étude de leur forme que de leur contenu.

Ce travail, qui demande une mise en série autant qu'une analyse minutieuse de ces documents, rend plus que jamais nécessaire le dialogue de spécialités disciplinaires parfois peu habituées à mettre en commun leurs compétences (paléographie, linguistique, droit, histoire, au-delà de la papyrologie même). Et ce n'est pas le moindre de ses mérites.

Hélène Ménard

EA 4424-CRISES,

Université Paul Valéry Montpellier 3;

60 On y trouvera aussi le compte rendu du premier workshop, tenu en février 2015.

61 S. Ammirati, M. Fressura, D. Mantovani, “Curiales e cohortales in P. Gen. Lat. inv. 6. Una nuova versione di una costituzione di Onorio e Teodosio II del 423 ", ZRG RA I32 (2015) [à paraître].

62 L'editio princeps a été proposée par P. Radiciotti, “Interpretatio del Codice theodosiano in un papiro di Ginevra ", SEP 8 (2OII), p. IO5-III.

63 Sur les travaux de Dario Mantovani concernant la culture juridique et en particulier la pertinence d'une “littérature» juridique, voir ses conférences au Collège de France en avril 2013 (http://www.college-de-france.fr/site/john-scheid/guestlecturer20I3-04-02-IIhoo.htm et liens suivants pour l'ensemble des conférences), à paraitre aux Belles Lettres. 